\title{
Mutagenesis of conserved tryptophan residues within the receptor-binding domain of intimin: influence on binding activity and virulence
}

\author{
Stephen Reece, ${ }^{1}$ Cameron P. Simmons, ${ }^{1}$ Robert J. Fitzhenry, ${ }^{2}$ \\ Miranda Batchelor, ${ }^{1}$ Christine Hale, ${ }^{1}$ Stephen Matthews, ${ }^{3}$ \\ Alan D. Phillips, ${ }^{2}$ Gordon Dougan ${ }^{1}$ and Gad Frankel ${ }^{1}$
}

Author for correspondence: Gad Frankel. Tel: +44 207594 5253. Fax: +44 2075945255. e-mail: g.frankel@ic.ac.uk
1,3 Centre for Molecular Microbiology and Infection ${ }^{1}$ and Centre for Structural Biology3, Department of Biological Sciences, Imperial College of Science, Technology and Medicine, London SW7 2AZ, UK
2 Centre for Paediatric Gastroenterology, Royal Free Hospital, London NW3 2QG, UK

\begin{abstract}
Intimate bacterial adhesion to intestinal epithelium is a pathogenic mechanism shared by several human and animal enteric pathogens, including enteropathogenic and enterohaemorrhagic Escherichia coli and Citrobacter rodentium. The proteins directly involved in this process are the outermembrane adhesion molecule intimin and the translocated intimin receptor, Tir. The receptor-binding activity of intimin resides within the carboxy terminus 280 aa (Int280) of the polypeptide. Four tryptophan residues, W117/776, W136/795, W222/881 and W240/899, are conserved within different Int280 molecules that otherwise show considerable sequence variation. In this study the influence of site-directed mutagenesis of each of the four tryptophan residues on intimin-Tir interactions and on intimin-mediated intimate attachment was determined. The mutant intimins were also studied using a variety of in vitro and in vivo infection models. The results show that all the substitutions modulated intimin activity, although some mutations had more profound effects than others.
\end{abstract}

Keywords: Citrobacter rodentium, EPEC, EHEC, Tir

\section{INTRODUCTION}

Enteropathogenic (EPEC) and enterohaemorrhagic (EHEC) Escherichia coli are important causes of severe infantile diarrhoeal disease (Nataro \& Kaper, 1998). EPEC and EHEC colonize the gastrointestinal mucosa and, by subverting intestinal epithelial cell function, produce a characteristic histopathological feature known as the 'attaching and effacing' (A/E) lesion (Frankel et al., 1998a; Kaper et al., 1998). The A/E lesion is characterized by localized destruction (effacement) of brush border microvilli, intimate attachment of the bacillus to the host-cell plasma membrane and the formation of an underlying pedestal-like structure in the host cell consisting of polymerized actin, ezrin, talin and myosin (Frankel et al., 1998a; Kaper et al., 1998), as well as WASP (Wiskott-Aldrich syndrome family of pro-

\footnotetext{
Abbreviations: A/E lesion, 'attaching and effacing' lesion; EHEC, enterohaemorrhagic Escherichia coli; EPEC, enteropathogenic Escherichia coli; FAS, fluorescent actin stain; LEE, locus of enterocyte effacement; MBP, maltose-binding protein; Tir, translocated intimin receptor.
}

teins) and the Arp2/3 complex (Kalman et al., 1999). E. coli capable of forming A/E lesions have also been recovered from diseased cattle, dogs, cats, rabbits and pigs (Nataro \& Kaper, 1998). In mice, Citrobacter rodentium colonizes gut enterocytes via $\mathrm{A} / \mathrm{E}$ lesion formation and, like EHEC in humans, causes disease in the large bowel (Barthold et al., 1976; Schauer \& Falkow, 1993a).

The genes encoding the A/E phenotype are encoded on a pathogenicity island termed the locus of enterocyte effacement (LEE) (McDaniel et al., 1995). The majority of the LEE genes are organized in five polycistronic operons (LEE1, LEE2, LEE3, tir and LEE4) (Mellies et al., 1999). LEE1, LEE2 and LEE3 encode components of a type III secretion system (TTSS), LEE4 encodes proteins secreted by the TTSS, termed E. coli secreted proteins (Esps) (Elliott et al., 1998; Frankel et al., 1998a), and the tir operon encodes the outer-membrane adhesion molecule, intimin (Jerse \& Kaper, 1991; Jerse et al., 1990), the translocated intimin receptor, Tir (Deibel et al., 1998; Kenny et al., 1997), and CesT (the Tir chaperone) (Abe et al., 1999; Elliott et al., 1999). 
Studies on intimin in EPEC, EHEC and C. rodentium have demonstrated its importance in bacterial colonization and virulence (Dean-Nystrom et al., 1998; Donnenberg et al., 1993b; McKee et al., 1995; Marches et al., 2000; Schauer \& Falkow, 1993b). The receptorbinding domain of intimin molecules is localized to the C-terminal 280 aa (Int280) (Frankel et al., 1994, 1995). Furthermore, based on sequence variation within Int280, five distinct intimin subtypes $(\alpha, \beta, \gamma, \delta$ and $\varepsilon)$ have been described (Adu-Bobie et al., 1998; Oswald et al., 2000). Recently, the structure of Int $280 \alpha$ complexed with Tir was determined by NMR and X-ray crystallography (Batchelor et al., 2000; Luo et al., 2000). The global fold of Int $280 \alpha$ shows three globular domains. The first two domains (residues 1-91 and 93-181) each comprise $\beta$-sheet sandwiches that resemble the immunoglobulin super family (IgSF). Despite no significant sequence homology, the topology of the Cterminal domain (residues 183-280) is reminiscent of the C-type lectin domains (CTLD), a family of proteins responsible for cell-surface carbohydrate recognition (Weis \& Drickamer, 1996).

The overall organization and structure of the receptorbinding domain of other intimin types are predicted to be similar to Int $280 \alpha$, despite the fact that sequence analysis of the Int280 domains reveals high levels of sequence diversity. Nevertheless, four Trp residues (W117/776, W136/795, W222/881 and W240/899) (positions numbered according to Int $280 \alpha /$ whole inti$\min \alpha)$ are conserved in all intimins sequenced to date. Two of the four Trp residues (W222/881 and W240/ 899) are part of short conserved islands in the CTLD modules that have been hypothesized to play a role in receptor-binding activity. In this report we describe results of site-directed mutagenesis of the Trp residues. Using in vitro (HEp-2 cells) and in vivo (mice) infection models, as well as biochemical approaches, we report diverse modulation of intimin activity.

\section{METHODS}

Bacterial strains and plasmids. Bacterial strains used in this study include wild-type EPEC strain E2348/69 (O127:H6) (Levine et al., 1985), eae deletion mutants of E2348/69, strain CVD206 (Donnenberg \& Kaper, 1991), C. rodentium strain DBS255 (Schauer \& Falkow, 1993b), and E. coli strains XL-1 Blue and BL21. Bacterial strains were grown in L-broth. Media were supplemented with $50 \mu \mathrm{g}$ kanamycin $\mathrm{ml}^{-1}, 30 \mu \mathrm{g}$ chloramphenicol $\mathrm{ml}^{-1}$ or $100 \mu \mathrm{g}$ ampicillin $\mathrm{ml}^{-1}$. Plasmids are listed in Table 1.

Site-directed mutagenesis. Site-directed mutagenesis was performed using the QuickChange Site-directed Mutagenesis Kit (Stratagene), following the manufacturer's instructions, employing plasmid pCVD438 that encodes intimin $\alpha$ (Donnenberg \& Kaper, 1991) as a template. Complimentary mutagenesis oligonucleotide pairs, incorporating single amino acid substitutions, were as follows. Sense oligonucleotides: W776/117A， 5'-GTTACCCACTGTAGCTTTGCAATATGG-3'; W797/136A, 5'-GGAAAATATACAGCTCGCTCAGCAAATCC-3'; W881/222A, 5'-CTTTAAAGCAGCTGGGGCTGCAAATAAATATG-3'; W899/240A, 5'-GACTATAATTTCAGCTGTACAACAAACAGC-3’. Antisense oligo- nucleotides: W776/117A, 5'-CCATATTGCAAAGCTACAGTGGGTAAC-3'; W795/136A, 5'-GGATTTGCTGAGCGAGCTGTATATTTTCC-3'; W881/222A， 5'-CATATTTATTTGCAGCCCCAGCTGCTTTAAAG-3'; W899/240A, 5'-GCTGTTTGTTGTACAGCTGAAATTATAGTC-3'.

Mutated plasmids containing staggered nicks were generated by extension of primers annealed to opposite strands of the denatured plasmid by temperature cycling $\left(1\right.$ cycle of $95^{\circ} \mathrm{C}$ for $30 \mathrm{~s}$, then 16 cycles of $95^{\circ} \mathrm{C}$ for $30 \mathrm{~s}, 55^{\circ} \mathrm{C}$ for $1 \mathrm{~min}$ and $68^{\circ} \mathrm{C}$ for $18 \mathrm{~min}$ ) in the presence of the high fidelity $P f u$ DNA polymerase. Synthesized DNA containing the desired mutation was selected from the original DNA template by incubation with $D p n \mathrm{I}$ at $37^{\circ} \mathrm{C}$ for $1 \mathrm{~h}$, on the basis that dammethylated parental DNA template would be susceptible to digestion, whereas the newly synthesized unmethylated mutated plasmid would not. Nicks in the plasmid were repaired following transformation of $1 \mu \mathrm{l}$ of the synthesized products into competent E. coli XL-1 Blue cells. Chloramphenicolresistant transformants were randomly selected and inoculated into overnight L-broth cultures for use in plasmid minipreps (Qiagen). Correct incorporation of each mutation was monitored by DNA sequencing using an automated DNA sequencer. The mutated plasmids were then transformed into an eae deletion mutant of EPEC strain CVD206 (Donnenberg \& Kaper, 1991).

Construction of maltose-binding protein (MBP)-Int280 fusions. The mutagenized pCVD438-derivative plasmids were then used as templates to amplify the DNA fragments encoding the mutated Int 280 regions by PCR using one set of primers (Forward primer, 5'-GGAATTCATTACTGAGATTAAGGCT-3'; Reverse primer, 5'-CGGGATCCTTATTTTACACAAGTGGC-3'). Following digestion with EcoRI and $\mathrm{BamHI}$ the DNA fragments were subcloned into pMAL-c2 for expression as MBP fusions (Table 1).

Gel overlays. Purified His-Tir-M, expressed from pICC26 in E. coli BL21, was purified as described by Hartland et al. (1999). MBP-Int280 derivatives were expressed from recombinants pMal-c2 and purified from E. coli XL-1 Blue as described by Frankel et al. (1994). His-Tir-M was separated by SDS-PAGE and blotted onto a nitrocellulose membrane which was blocked with $10 \%$ skim-milk in PBS $/ 0 \cdot 1 \%$ Tween-20 overnight. The nitrocellulose membranes were reacted with $5 \mu \mathrm{g}$ of the purified MBP-Int280 fusions $\mathrm{ml}^{-1}$ or MBP in PBS $/ 0 \cdot 1 \%$ Tween-20 for $2 \mathrm{~h}$ and washed twice for $5 \mathrm{~min}$ in PBS $/ 0 \cdot 1 \%$ Tween-20. MBP-Int280 fusion proteins binding to Tir were detected with anti-MBP antiserum (1:2000 for $1 \mathrm{~h})$ and then anti-rabbit antibodies conjugated to alkaline phosphatase (1:2000 for $1 \mathrm{~h}$ ) as described by Hartland et al. (1999).

Fluorescent actin stain (FAS) assays, detection of surface intimin expression and Western blots. Expression of the intimin derivatives on the surface of CVD206 and their ability to mediate $\mathrm{A} / \mathrm{E}$ lesion formation was assessed using rabbit Int $280 \alpha$ antiserum (Frankel et al., 1998b) and the FAS test developed by Knutton et al. (1989), respectively. Briefly, HEp2 cells were grown to approximately $80 \%$ confluency on coverslips in 24-well plates. Cells were infected with $10 \mu \mathrm{l}$ static overnight L-broth cultures in medium lacking antibiotics for $3 \mathrm{~h}$. The monolayers were then washed with PBS, fixed by the addition of $300 \mu 110 \%$ formalin for $20 \mathrm{~min}$ and washed again. For detection of EPEC-associated intimin, coverslips were incubated with the anti-Int $280 \alpha$ polyclonal antiserum (1:50 dilution) for $45 \mathrm{~min}$ in Dulbecco's modified Eagle medium (DMEM) and then with a secondary tetramethylrhodamine isothiocyanate (TRITC)-labelled anti-rabbit antibody (1:250 dilution) for $30 \mathrm{~min}$. Following washes, the 
Table 1. List of plasmids used

\begin{tabular}{|c|c|c|}
\hline Plasmid & Description & Reference \\
\hline pCVD438 & pACYC184 encoding intimin $\alpha$ & Donnenberg \& Kaper (1991) \\
\hline pICC201 & pCVD438 encoding intimin W776A & This study \\
\hline pICC202 & pCVD438 encoding intimin W797A & This study \\
\hline pICC203 & pCVD438 encoding intimin W881A & This study \\
\hline pICC62 & pCVD438 encoding intimin W8896A & Batchelor et al. (2000) \\
\hline pMal-C2 & $\begin{array}{l}\text { Cloning vector generating translational fusions with } \\
\text { MBP }\end{array}$ & New England Biolabs \\
\hline pICC22 & pMal encoding MBP-Int $280 \alpha$ & Frankel et al. (1994) \\
\hline pICC209 & pMal encoding $\mathrm{MBP}-\mathrm{Int} 280_{\mathrm{w} 117 \mathrm{~A}}$ & This study \\
\hline pICC210 & pMal encoding MBP-Int $280_{\mathrm{w} 136 \mathrm{~A}}$ & This study \\
\hline pICC211 & pMal encoding MBP-Int $280_{\mathrm{w} 222 \mathrm{~A}}$ & This study \\
\hline pICC63 & pMal encoding $\mathrm{MBP}-\mathrm{Int} 280_{\mathrm{w} 240 \mathrm{~A}}$ & Batchelor et al. (2000) \\
\hline pICC18 & pET28a encoding Tir-M & Hartland et al. (1999) \\
\hline
\end{tabular}

monolayers were permeabilized with $0 \cdot 1 \%$ Triton X-100 for $4 \mathrm{~min}$. Filamentous actin was subsequently stained with $5 \mu \mathrm{l}$ fluorescein-isothiocyanate-labelled phalloidin in PBS $\left(0 \cdot 1 \mu \mathrm{g} \mathrm{ml}^{-1}\right)$ for $20 \mathrm{~min}$ (FAS test). Following extensive washes with PBS, the infected cultures were visualized by fluorescence microscopy.

Expression of the intimin derivatives was also determined by Western blotting. Briefly, stationary-phase L-broth cultures were diluted 1:100 in DMEM and incubated for $3 \mathrm{~h}$ at $37{ }^{\circ} \mathrm{C}$. An equivalent of an $\mathrm{OD}_{600}$ of 0.5 was loaded onto a $7.5 \%$ SDSpolyacrylamide gel as described (Adu-Bobie et al., 1998). The electrophoresed polypeptides were transferred to a nitrocellulose membrane and immunodetection of intimin was performed using anti-Int280, diluted 1:500 as described previously (Adu-Bobie et al., 1998; Frankel et al., 1998b).

Fluorescence-activated cell sorter (FACS) analysis of surfaceexpressed intimin by indirect immunofluorescence. CVD206(pCVD438) derivatives were grown overnight in $5 \mathrm{ml}$ L-broth. Cultures were diluted 1/100 in DMEM and grown to an $\mathrm{OD}_{600}$ of $0 \cdot 6-0 \cdot 8$. Bacteria were washed three times in PBS and fixed for $20 \mathrm{~min}$ in $3 \%$ formaldehyde in PBS. Bacteria were washed with PBS and incubated with anti-Int 280 polyclonal antisera (Adu-Bobie et al., 1998) for $30 \mathrm{~min}$ at room temperature. Bacteria were then washed with PBS and incubated with FITC-conjugated anti-rabbit IgG (Sigma) at room temperature for $30 \mathrm{~min}$. Bacteria were washed with PBS and 50000 events were acquired from a Beckman Dickinson FACS Analyser using the FL1 channel.

Challenge of mice with $\mathrm{C}$. rodentium. Female, specificpathogen-free, $\mathrm{C} 3 \mathrm{H} / \mathrm{Hej}$ mice (6-8 weeks old) were purchased from Harlan Olac. All mice were housed in individual ventilated cages with free access to food and water. Bacterial inoculums were prepared by culturing bacteria overnight at $37^{\circ} \mathrm{C}$ in $10 \mathrm{ml} \mathrm{L-broth} \mathrm{containing} 100 \mu \mathrm{g}$ nalidixic acid ml $\mathrm{m}^{-1}$ plus $50 \mu \mathrm{g}$ chloramphenicol $\mathrm{ml}^{-1}$. After incubation, bacteria were harvested by centrifugation and resuspended in a $1 \mathrm{ml}$ volume of PBS. Unanaesthetized mice were then orally inoculated with $200 \mu \mathrm{l}$ of the bacterial suspension using a gavage needle. The viable count of the inoculum was determined by retrospective plating on L-agar containing appropriate antibiotics.

Measurement of pathogen burden. Mice were killed 14 days post-infection by cervical dislocation. The distal $6 \mathrm{~cm}$ of colon was removed and weighed after removal of faecal pellets. Colons were then homogenized mechanically using a Seward 80 Stomacher and the number of viable bacteria in colonic homogenates was determined by viable count on L-agar containing appropriate antibiotics.

\section{RESULTS}

\section{The effect of mutagenesis on intimin expression and A/E lesion formation in vitro}

Four tryptophans, namely W117/776, W136/795, W222/881 and W240/899, lie in the Tir-binding domain of intimin (D2 and D3 of Int280) (Batchelor et al., 2000). These are distributed throughout the structure (Fig. 1), and based on sequence alignment all four are conserved

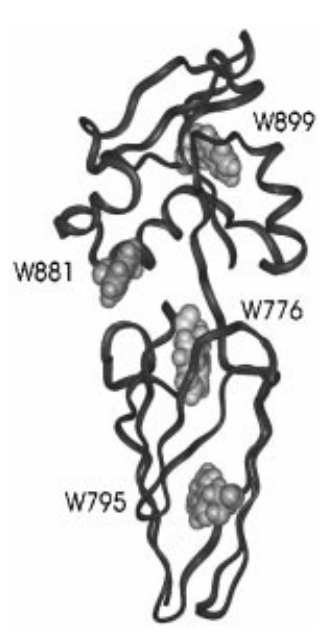

Fig. 1. Schematic representation of the structure of D2 and D3 of Int280 comprising the Int190 super domain (Batchelor et al., 2000). The location within the super domain of the four Trp residues selected for mutagenesis is indicated. Numbers by the amino acid residues represent positions in the full-length intimin $\alpha$. 


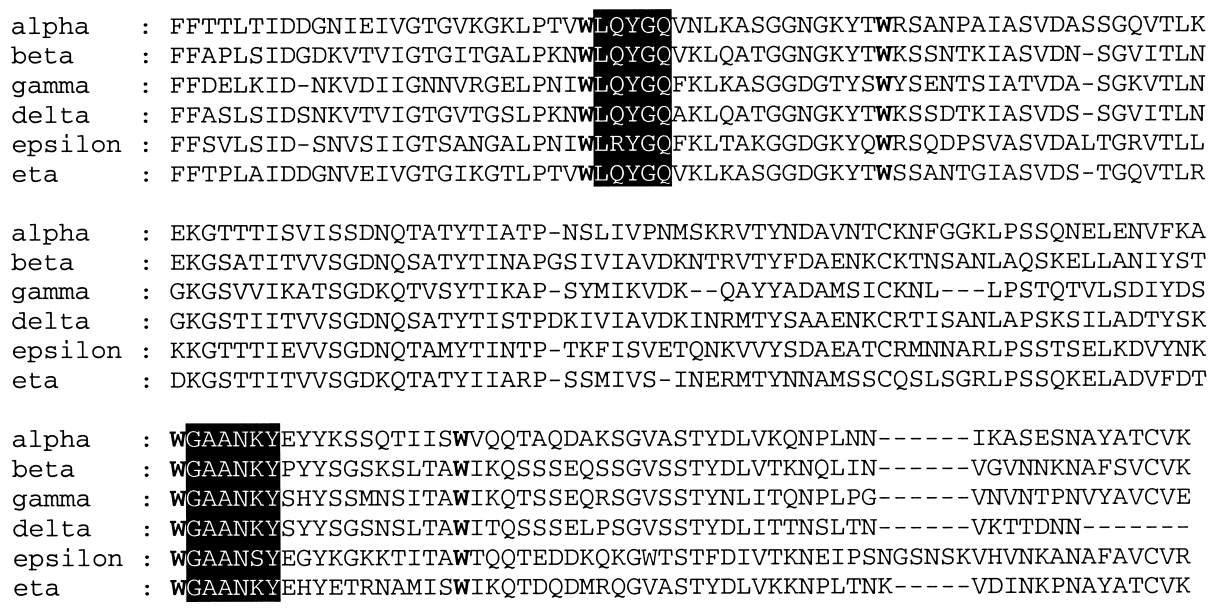

Fig. 2. Amino acid sequence alignment of the different D2 and D3 domains of the different Int280 types. Sequence searches were performed using WUBLAST and alignment was performed using CLUSTAL W and BOXSHADE on the EMBL server. Conserved motifs found in all the different intimin types are highlighted and the four Trp residues are shown in bold type.

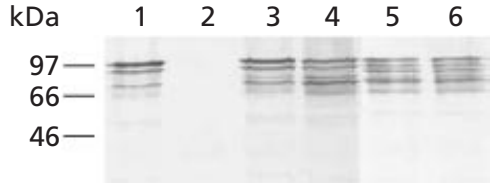

Fig. 3. Western blot of CVD206(pCVD438) derivative wholecell lysates. The nitrocellulose membrane was probed with the Int $280 \alpha$ antiserum. Full-length intimin was detected only in strains harbouring pCVD438 derivatives. Lanes: 1 , CVD206(pCVD438); 3, CVD206(pICC201); 4, CVD206(pICC202); 5 , CVD206(pICC203); 6, CVD206(pICC62). No intimin was detected in CVD206 (lane 2).

within all intimin types (Fig. 2). Although W240/889 is buried proximal to the residues involved in Tir-binding, experimental evidence supports a role as a structural scaffold for the Tir binding site within D3 (Batchelor et al., 2000). W222/W881 is also particularly interesting as it lies in one of the most highly conserved regions (WAGGANKY) and is present at the interface between D2 and D3 (Figs 1 and 2). W117/776 is buried within D2 and lies proximal to the D2/D3 interface. W136/W795 lies centrally within D2 and appears to fulfil largely structural requirements for the folding of this domain (Fig. 1).

To determine the importance of the W117/776, W136/ 795 and W222/881 residues for intimin-mediated A/E lesion formation on HEp-2 cells, the mutations were introduced, individually, into pCVD438 harbouring the eae gene encoding intimin $\alpha$ (Donnenberg \& Kaper, 1991), generating plasmids pICC201 (intimin W117/ 776), pICC202 (intimin W136/776) and pICC203 (intimin W222/881) (Table 1). The mutant pCVD438 derivatives were introduced into CVD206 (Donnenberg \& Kaper, 1991), which harbours a null deletion in eae, and the CVD206 derivatives were subjected to a number of biological assays designed to determine the influence of the mutations on intimin function in vitro. Western blot analysis of whole-cell lysates prepared from the different CVD206(pCVD438) derivatives reacted similarly with anti-Int $280 \alpha$ antiserum (Fig. 3). No reactivity was seen with CVD206, suggesting that the multiple bands are intimin degradation products. Similar patterns of intimin blots have been reported previously (AduBobie et al., 1998; Frankel et al., 1998b; Reece et al., 2001). Indirect immunofluorescence staining showed that after a $3 \mathrm{~h}$ incubation with HEp-2 cells, all the adhering CVD206(pCVD438)-derivatives, but not CVD206, expressed intimin (Fig. 4). Surface intimin expression was quantified using FACS analysis. Although CVD206(pICC201) presented somewhat higher fluorescent intensity, an overall similar level of surface intimin expression was observed with all the CVD206(pCVD438) derivatives, while no signal was observed using CVD206 (Fig. 5).

Since expression of intimin was not markedly affected by the introduction of site-directed mutations, the ability of the different CVD206(pCVD438) derivatives to induce actin polymerization in infected HEp-2 cells (FAS test; Knutton et al., 1989), a marker for A/E lesion formation, was determined. This assay showed that like CVD206 and CVD206(pICC62) (W240/899A) (Fig. 4; Batchelor et al., 2000), CVD206(pICC202) (W136/795A) was unable to induce actin polymerization while CVD206(pICC201) (W117/776A) and CVD206(pICC203) (W222/881A) were FAS-positive (Fig. 4).

\section{Binding of the modified intimins to Tir}

To determine if the site-directed mutagenesis data and the phenotypes described above were due an impaired binding to Tir, Int280 domains harbouring the mutation 

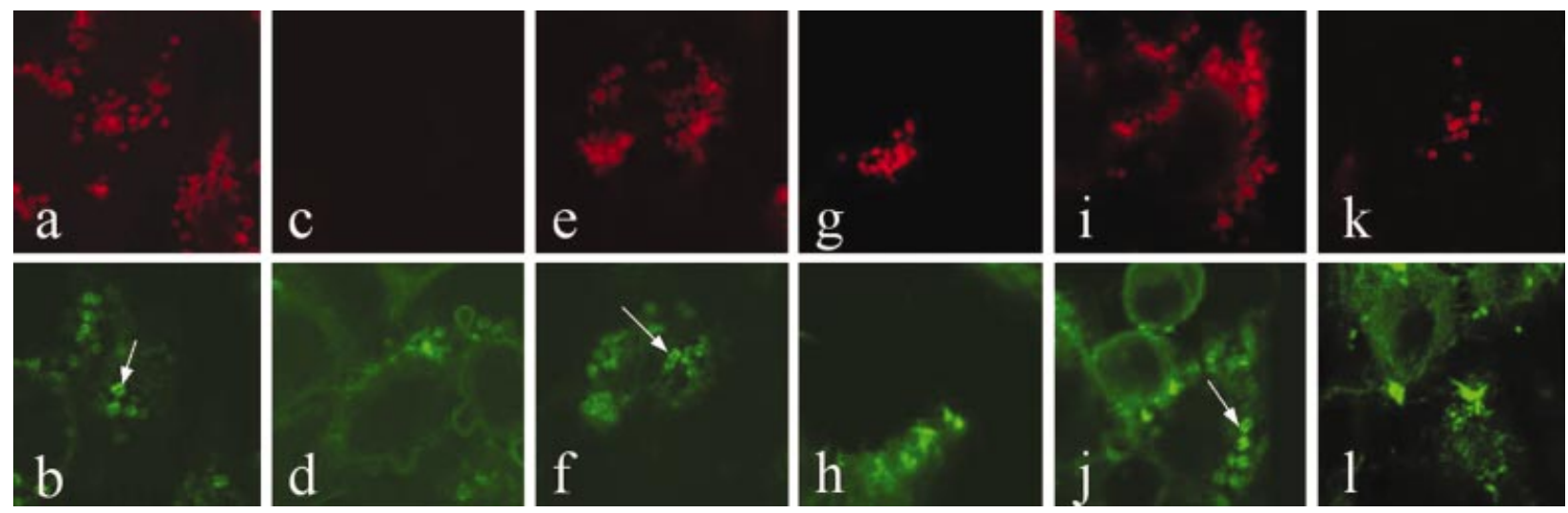

Fig. 4. Intimin fluorescence $(a, c, e, g, i, k)$ and FAS test $(b, d, f, h, j, l)$ of CVD206(pCVD438) derivatives. Infected HEp-2 cells were stained $3 \mathrm{~h}$ post-infection. A similar intensity of intimin staining was seen for all the CVD206(pCVD438) derivatives. (a) CVD206(pCVD438); (e) CVD206(plCC201); (g) CVD206(pICC202), (i) CVD206(pICC203) and (k) CVD206(pICC62). No staining was observed with CVD206 (c). CVD438(pCVD438) (b), CVD206(pICC201) (f) and CVD206(pICC203) (j), but not CVD206 (d), CVD206(plCC202) (h) or CVD206(plCC62) (I), produced a positive FAS reaction (arrows).
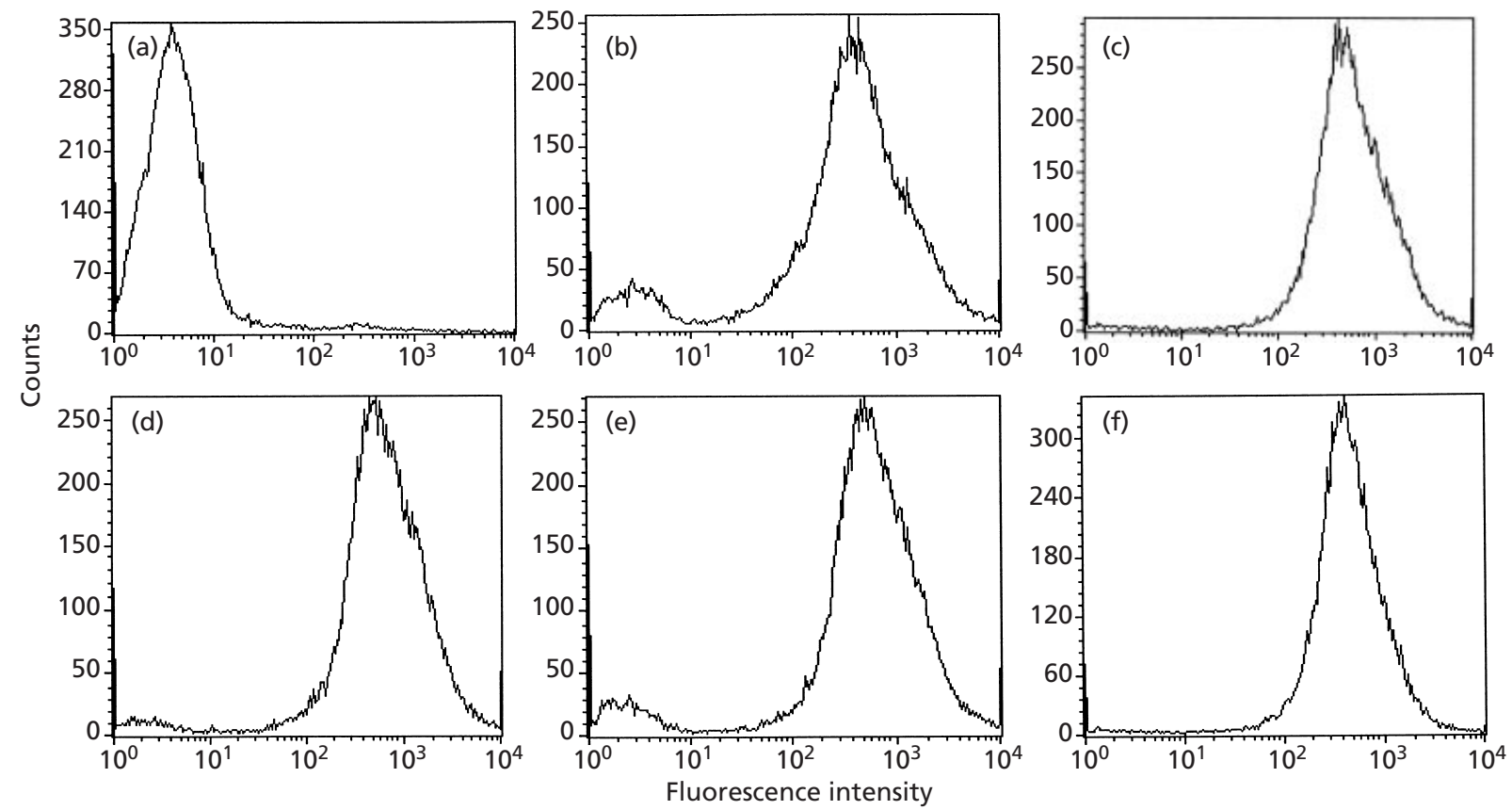

Fig. 5. Detection of surface intimin expression by FACS. (a) CVD206, geometric mean =428; (b) CVD206(pCVD438), geometric mean $=284 \cdot 22$; (c) CVD206(pICC201), geometric mean = 588.33; (d) CVD206(pICC202), geometric mean = 537.29; (e) CVD206(pICC203), geometric mean = 427.52; (f) CVD206(pICC62), geometric mean $=401 \cdot 41$. Surface intimin expression was not affected by mutagenesis; a comparable level of fluorescent intensity was seen using CVD206 expressing the wild-type or the mutated intimin polypeptides. Intimin was detected on a small proportion of CVD206(pCVD438) and CVD206(pICC203), but not on CVD206.

were amplified by PCR and cloned into pMALc-2. This allowed us to express the Int 280 domains as translational fusions with MBP. The MBP-Int280 fusion proteins were purified by affinity chromatography (Frankel et al., 1994) and equal amounts (Fig. 6) were used together with purified Tir-M (consisting of the intimin-binding region of Tir; Hartland et al., 1999) in a gel-overlay binding assay. This revealed that MBP-Int280, MBPInt $280_{\mathrm{w} 117 / 776}$, MBP-Int $280_{\mathrm{w} 222 / 881 \mathrm{~A}}$ and MBPInt $280_{\mathrm{W} 136 / 795 \mathrm{~A}}$ bound to the immobilized Tir-M, al- 


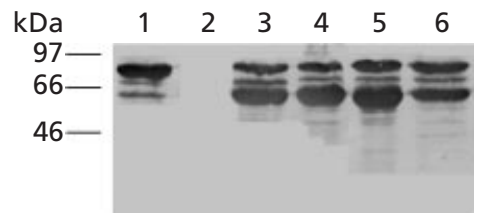

Fig. 6. Affinity-purified MBP-Int280 derivatives were reacted with Int280 polyclonal antiserum. Similar levels and patterns were observed for the different fusion proteins: MBP-Int280 (lane 1), MBP-Int280 ${ }_{\text {W117A }}$ (3), MBP-Int280 ${ }_{\text {M136A }}$ (4), MBP-Int280 ${ }_{\text {W222A }}$ (5) and MBP-Int280 W240A $_{\text {(6). The }}$ (6) Tht 280 antiserum did not react with MBP only (lane 2).

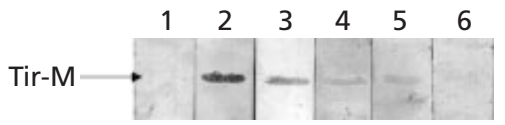

Fig. 7. Detection of Int280-Tir interaction using gel overlays. Immobilized Tir-M was overlaid with the different MBP-Int280 derivatives. Binding was detected using rabbit MBP antiserum. MBP-Int280 (lane 2), MBP-Int280 ${ }_{\text {W117A }}$ (3), MBP-Int280 ${ }_{\text {w136A }}$ (4) and MBP-Int280 ${ }_{\text {W222A }}$ (5) interacted with Tir-M. MBP only (1) and MBP-Int280 ${ }_{\text {W240A }}(6)$ did not bind Tir-M.

though the latter two seemed to bind somewhat less efficiently. No binding was detected with MBPInt $280_{\mathrm{W}_{240 / 899 \mathrm{~A}}}$ or MBP only (Fig. 7 ).

\section{Colonic colonization of mice challenged with DBS255(pCVD438) derivatives}

C. rodentium causes transmissible colonic hyperplasia in mice (Barthold et al., 1976), an infection associated with the formation of $\mathrm{A} / \mathrm{E}$ lesions similar to those described for human EPEC infection (Schauer \& Falkow, 1993a). Accordingly, this model provided an opportunity to evaluate the in vivo biological properties of EPEC intimin mutants in mice. To evaluate the effect of site-directed mutagenesis on the biological activity of intimin in vivo, the different pCVD438 derivatives were transformed into DBS255, which harbours a null deletion in eae, and used to infect mice orally. Fourteen days post-challenge, measurement of pathogen burden in the colons of these mice revealed marked differences in the ability of each strain to colonize the colonic epithelium. Mice infected with DBS255(pCVD438) had high numbers of challenge bacteria in their colons (Fig. 8a) and induced colonic hyperplasia as measured by colonic weight (Fig. 8b). Mice infected with DBS255(pICC201) (W117/776A), DBS255(pICC202) (W136/795A), DBS255(pICC203) (W222/881A) and DBS255(pICC62) (W240/899A) had fewer challenge bacteria in their colons compared to similar mice challenged with DBS255(pCVD438). However, the levels were still somewhat higher than those observed in DBS255-challenged animals (Fig. 8a). Interestingly, the colonic weights of mice challenged with the different DBS255 mutant derivatives were similar to those challenged with DBS255 (Fig. 8b).

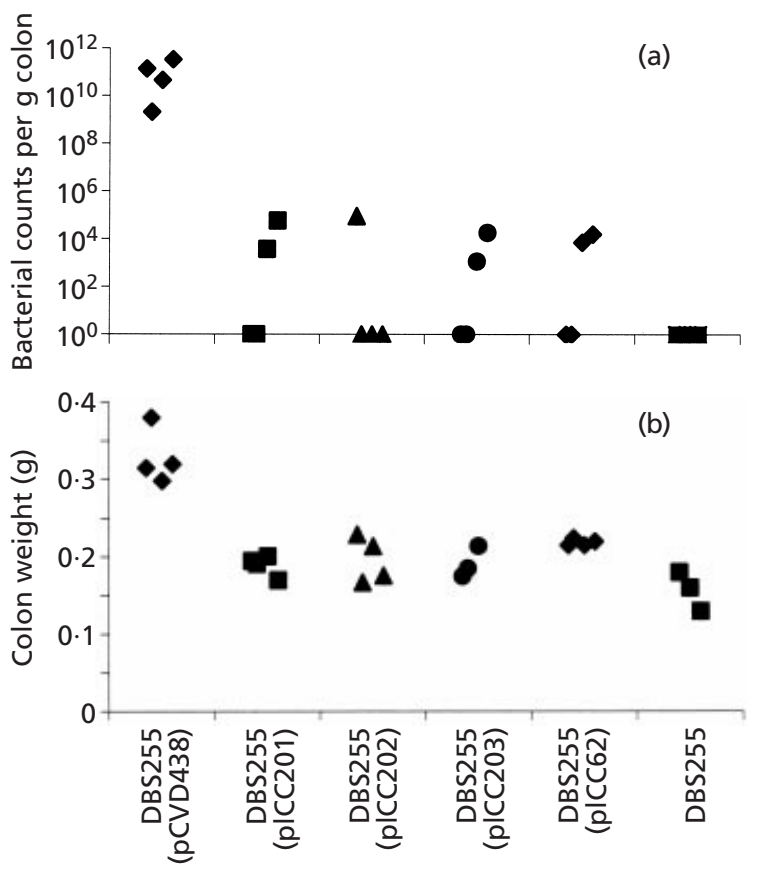

Fig. 8. Virulence of $C$. rodentium strains expressing mutated intimin molecules. (a) The data depict the number of $C$. rodentium cells recovered from colonic tissue of individual mice orally infected 14 days previously. Mice infected with DBS255(pCVD438) had high pathogen burdens. In contrast, mice infected with DBS255(pICC201), DBS255(pICC202), DBS255(plCC203) and DBS255(plCC62) had significantly lower bacterial loads $(P<0.05)$. No bacteria were recovered from mice infected with DBS255. (b) The distal $6 \mathrm{~cm}$ of the colon was weighed 14 days post challenge. The weights of colons from mice infected with DBS255(pCVD438) were significantly greater than colons from mice infected with BBS255 or DBS255 expressing any of the intimin mutants $(P<0.05)$.

\section{DISCUSSION}

In the present investigation we targeted the four Trp residues within the receptor-binding superdomain of intimin (Batchelor et al., 2000) for site-directed mutagenesis. These residues were selected because: (i) they are conserved among all the different intimin types reported thus far; (ii) Trp residues are large hydrophobic moieties that potentially have key structural roles and can be involved in protein interactions; and (iii) two of the residues are part of conserved motifs (Fig. 2) and for this reason were hypothesized to have a role in the binding activity of intimin (Adu-Bobie et al., 1998).

Previous work has shown that W240/899, located on a conserved loop on the D3 domain, is important for intimin-Tir interactions and $\mathrm{A} / \mathrm{E}$ lesion formation, despite the fact that it does not directly contact Tir (Batchelor et al., 2000). The other residue that forms part of a conserved island within D3 is W222/881. This residue lies at the D2 interface and, together with the adjacent Tyr residues and W117/776, stabilizes a surface pocket, which may be involved in intermolecular interactions, perhaps with a receptor other than Tir. Indeed, mutating either W117/776 or W222/881 did not abolish 
the ability of intimin to bind Tir. In addition, EPEC expressing intimin W117/776A or W222/881A induced A/E lesions on HEp-2 cells. In contrast, a mutation at position W136/795, which is located at the core of D2, resulted in an intimin molecule that when presented on the surface of EPEC could not mediate A/E lesion formation on HEp-2 cells. This was despite the fact that on gel overlays Int280 W136/795A bound to immobilized Tir-M. Importantly, we demonstrated using Western blots, immunofluorescence and FACS that neither mutation affected the level or surface localization of intimin.

The mouse pathogen C. rodentium was used to assess the effect of mutagenesis on the function of intimin in vivo. The expression of intimin $\alpha$ in C. rodentium DBS255 restores the ability of the strain to colonize the mouse colon and to induce colonic hyperplasia (Higgins et al., 1999b). In addition, intimin $\alpha$ can bind Tir from $C$. rodentium (Hartland et al., 2000). Evaluating intimin mutants in the C. rodentium infection model, where the bacteria have to compete with the normal intestinal flora and establish a long-term association with the mucosal surface, demonstrated that mutation at each of the Trp residues resulted in an attenuated phenotype. No detectable colonic hyperplasia and a reduced pathogen burden in comparison with DBS255(pCVD438) were observed. Nevertheless, in a few individual mice the level of colonization by each of the mutants was higher than that observed for DBS255. No C. rodentium bacteria were recovered at any time from the colons of DBS255-infected mice. We have reported similar results for other intimin mutations (Reece et al., 2001). The absence of detectable colonic hyperplasia in animals infected with C. rodentium derivatives expressing intimin mutants may suggest that a sustained and substantial level of pathogen colonization is required to trigger colonic pathology. Alternatively, these intimin mutations may affect the in vivo stability of the molecule, or potentially, its ability to interact with other receptors in the mouse colon.

Substitution W240/899A produced the most extreme phenotype. This intimin did not bind Tir, nor induce A/E lesions on HEp-2 cells or colonic hyperplasia in vivo. As reported, this residue might have an important structural role within the Tir-binding site (Batchelor et al., 2000). The phenotype associated with W136/795 differed from W240/899 only by the fact that the strain still bound Tir. This indicates that binding to Tir, although necessary, may not be sufficient for production of A/E lesions or that reduced intimin/Tir affinity could not mediate A/E lesion formation. W136/795 is believed to have a structural role in maintaining the integrity of the D2/D3 super domain within intimin. In contrast, residues W222/881 and W117/776, which exhibited similar phenotypes (including binding to Tir, A/E lesion formation on HEp-2 cells with reduced colonization of the mouse colon and no hyperplasia), seem to play a part in a further function of intimin. These conserved residues perhaps stabilize a binding pocket that is implicated in a host-receptor interaction, possibly $\beta 1$ integrins (Frankel et al., 1996). Indeed, oral infection of mice with live wild-type C. rodentium or intracolonic inoculation of dead bacteria [wild-type and DBS2559(pCVD438)] induces a pronounced colitis (Higgins et al., 1999a). This response was not observed in mice inoculated with any of the intimin mutants of C. rodentium.

Intimin is an abundant outer-membrane adhesion molecule that is essential for full virulence both in human volunteers (Donnenberg et al., 1993a) and animal models (Dean-Nystrom et al., 1998; Donnenberg et al., 1993b; McKee et al., 1995; Schauer \& Falkow, 1993b). As such it has potential as a vaccine component against A/E-lesion-forming bacterial pathogens. Indeed, we have recently shown that immunization with Int 280 can protect mice from oral infection with C. rodentium (Ghaem-Maghami et al., 2001). However, the fact that intimin can mediate colonic hyperplasia on its own (Higgins et al., 1999a) means that to reduce the risk of side effects, this activity of intimin would have to be eliminated. In this study we have produced a number of attenuated (detoxified) intimins. Their use as potential vaccines is currently being evaluated.

\section{ACKNOWLEDGEMENTS}

This work was supported by Action Research.

\section{REFERENCES}

Abe, A., de Grado, M., Pfuetzner, R. A., Sanchez-Sanmartin, C., Devinney, R., Puente, J. L., Strynadka, N. C. \& Finlay, B. B. (1999). Enteropathogenic Escherichia coli translocated intimin receptor, Tir, requires a specific chaperone for stable secretion. Mol Microbiol 33, 1162-1175.

Adu-Bobie, J., Frankel, G., Bain, C., Goncaleves, A. G., Trabulsi, L. R., Douce, G., Knutton, S. \& Dougan, G. (1998). Detection of intimin $\alpha, \beta, \gamma$, and $\delta$, four intimin derivatives expressed by attaching and effacing microbial pathogens. J Clin Microbiol 36, 662-668.

Barthold, S. W., Coleman, G. L., Jacoby, R. O., Livstone, E. M. \& Jonas, A. M. (1976). Transmissiable murine colonic hyperplasia. Vet Pathol 15, 223-236.

Batchelor, M., Prasannan, S., Daniell, S., Reece, S., Connerton, I., Bloomberg, G., Dougan, G., Frankel, G. \& Matthews, S. (2000). Structural basis for recognition of the translocated intimin receptor (Tir) by intimin from enteropathogenic Escherichia coli. EMBO J 19, 2452-2464.

Dean-Nystrom, E. A., Bosworth, B. T., Moon, H. W. \& O'Brien, A. D. (1998). Escherichia coli $\mathrm{O} 157: \mathrm{H} 7$ requires intimin for enteropathogenicity in calves. Infect Immun 66, 4560-4563.

Deibel, C., Kramer, S., Chakraborty, T. \& Ebel, F. (1998). EspE, a novel secreted protein of attaching and effacing bacteria, is directly translocated into infected host cells, where it appears as a tyrosine-phosphorylated $90 \mathrm{kDa}$ protein. Mol Microbiol 28, 463-474.

Donnenberg, M. S. \& Kaper, J. B. (1991). Construction of an eae deletion mutant of enteropathogenic Escherichia coli by using a positive-selection suicide vector. Infect Immun 59, 4310-4317.

Donnenberg, M. S., Tacket, C. O., James, S. P., Losonsky, G., 
Nataro, J. P., Wasserman, S. S., Kaper, J. B. \& Levine, M. M. (1993a). Role of the eaeA gene in experimental enteropathogenic Escherichia coli infection. J Clin Invest 92, 1412-1417.

Donnenberg, M. S., Tzipori, S., McKee, M. L., O’Brien, A. D., Alroy, J. \& Kaper, J. B. (1993b). The role of the eae gene of enterohemorrhagic Escherichia coli in intimate attachment in vitro and in a porcine model. J Clin Invest 92, 1418-1424.

Elliott, S. J., Wainwright, L. A., McDaniel, T. K., Jarvis, K. G., Deng, Y. K., Lai, L. C., McNamara, B. P., Donnenberg, M. S. \& Kaper, J. B. (1998). The complete sequence of the locus of enterocyte effacement (LEE) from enteropathogenic Escherichia coli E2348/69. Mol Microbiol 28, 1-4.

Elliott, S. J., Dubois, M. S., Hutcheson, S. W., Wainwright, L. A., Batchelor, M., Frankel, G., Knutton, S. \& Kaper, J. B. (1999). Identification of CesT, a chaperone for the type III secretion of Tir in Enteropathogenic Escherichia coli. Mol Microbiol 33, $1176-1189$.

Frankel, G., Candy, D. C., Everest, P. \& Dougan, G. (1994). Characterization of the C-terminal domains of intimin-like proteins of enteropathogenic and enterohemorrhagic Escherichia coli, Citrobacter freundii, and Hafnia alvei. Infect Immun 62, 1835-1842.

Frankel, G., Candy, D. C., Fabiani, E., Adu-Bobie, J., Gil, S., Novakova, M., Phillips, A. D. \& Dougan, G. (1995). Molecular characterization of a carboxy-terminal eukaryotic-cell-binding domain of intimin from enteropathogenic Escherichia coli. Infect Immun 63, 4323-4328.

Frankel, G., Lider, O., Hershkoviz, R., Mould, A. P., Kachalsky, S. G., Candy, D. C. A., Cahalon, L., Humphries, M. J. \& Dougan, G. (1996). The cell-binding domain of intimin from enteropathogenic Escherichia coli binds to $\beta 1$ integrins. J Biol Chem 271, 2035920364.

Frankel, G., Philips, A. D., Novakova, M., Batchelor, M., Hicks, S. \& Dougan, G. (1998a). Generation of Escherichia coli intiminderivatives with differing biological activities using site-directed mutagenesis of the intimin C terminus domain. Mol Microbiol 29, 559-570.

Frankel, G., Phillips, A. D., Rosenshine, I., Dougan, G., Kaper, J. B. \& Knutton, S. (1998b). Enteropathogenic and enterohaemorrhagic Escherichia coli: more subversive elements. Mol Microbiol 30, 911-921.

Ghaem-Maghami, M., Simmons, C. P., Daniell, S., Pizza, M., Lewis, D., Frankel, G. \& Dougan, G. (2001). Intimin-specific immune responses prevent bacterial colonization by the attaching-effacing pathogen Citrobacter rodentium. Infect Immun 69, 5597-5605.

Hartland, E. L., Batchelor, M., Delahay, R. M., Hale, C., Matthews, S., Dougan, G., Knutton, S., Connerton, I. \& Frankel, G. (1999). Binding of intimin from enteropathogenic Escherichia coli to Tir and to host cells. Mol Microbiol 32, 151-158.

Hartland, E. L., Huter, V., Higgins, L. M., Goncalves, N. S., Dougan, G., Phillips, A. D., MacDonald, T. T. \& Frankel, G. (2000). Expression of intimin gamma from enterohemorrhagic Escherichia coli in Citrobacter rodentium. Infect Immun 68, 4637-4646.

Higgins, L. M., Frankel, G., Connerton, I., Goncalves, N. S., Dougan, G. \& MacDonald, T. T. (1999a). Role of bacterial intimin in colonic hyperplasia and inflammation. Science 285, 588-591.

Higgins, L. M., Frankel, G., Douce, G., Dougan, G. \& MacDonald, T. T. (1999b). Citrobacter rodentium infection in mice elicits a mucosal Th1 cytokine response and lesions similar to those in murine inflammatory bowel disease. Infect Immun 67, 3031-3139.

Jerse, A. E. \& Kaper, J. B. (1991). The eae gene of enteropathogenic
Escherichia coli encodes a 94-kilodalton membrane protein, the expression of which is influenced by the EAF plasmid. Infect Immun 59, 4302-4309.

Jerse, A. E., Yu, J., Tall, B. D. \& Kaper, J. B. (1990). A genetic locus of enteropathogenic Escherichia coli necessary for the production of attaching and effacing lesions on tissue culture cells. Proc Natl Acad Sci U S A 87, 7839-7843.

Kalman, D., Weiner, O. D., Goosney, D. L., Sedat, J. W., Finlay, B. B., Abo, A. \& Bishop, J. M. (1999). Enteropathogenic E. coli acts through WASP and Arp2/3 complex to form actin pedestals. Nat Cell Biol 1, 389-391.

Kaper, J. B., Elliot, S., Sperandio, V., Perna, T. P., Maythew, G. F. \& Blatner, F. R. (1998). Attaching-and-effacing intestinal histopathology and locus of enterocyte effacement. In Escherichia coli and Other Shiga Toxin-Producing E. coli Strains, pp. 163-182. Edited by J. B. Kaper \& A. D. O’Brien. Washington, DC: American Society for Microbiology.

Kenny, B., DeVinney, R., Stein, M., Reinscheid, D. J., Frey, E. A. \& Finlay, B. B. (1997). Enteropathogenic E. coli (EPEC) transfers its receptor for intimate adherence into mammalian cells. Cell 91, 511-520.

Knutton, S., Baldwin, T., Williams, P. H. \& McNeish, A. S. (1989). Actin accumulation at sites of bacterial adhesion to tissue culture cells: basis of a new diagnostic test for enteropathogenic and enterohemorrhagic Escherichia coli. Infect Immun 57, 1290-1298.

Levine, M. M., Nataro, J. P., Karch, H., Baldini, M. M., Kaper, J. B., Black, R. E., Clements, M. L. \& O'Brien, A. D. (1985). The diarrheal response of humans to some classic serotypes of enteropathogenic Escherichia coli is dependent on a plasmid encoding an enteroadhesiveness factor. J Infect Dis 152, 550-559.

Luo, Y., Frey, E. A., Pfuetzner, R. A., Creagh, A. L., Knoechel, D. G., Haynes, C. A., Finlay, B. B. \& Strynadka, N. C. (2000). Crystal structure of enteropathogenic Escherichia coli intiminreceptor complex. Nature 405, 1073-1077.

Marches, O., Nougayrede, J. P., Boullier, S. \& 8 other authors (2000). Role of tir and intimin in the virulence of rabbit enteropathogenic Escherichia coli serotype O103:H2. Infect Immun 68, 2171-2182.

McDaniel, T. K., Jarvis, K. G., Donnenberg, M. S. \& Kaper, J. B. (1995). A genetic locus of enterocyte effacement conserved among diverse enterobacterial pathogens. Proc Natl Acad Sci U S A 92, 1664-1668.

McKee, M. L., Melton-Celsa, A. R., Moxley, R. A., Francis, D. H. \& O’Brien, A. D. (1995). Enterohemorrhagic Escherichia coli O157:H7 requires intimin to colonize the gnotobiotic pig intestine and to adhere to HEp-2 cells. Infect Immun 63, 3739-3744.

Mellies, J. L., Elliott, S. J., Sperandio, V., Donnenberg, M. S. \& Kaper, J. B. (1999). The Per regulon of enteropathogenic Escherichia coli: identification of a regulatory cascade and a novel transcriptional activator, the locus of enterocyte effacement (LEE)-encoded regulator (Ler). Mol Microbiol 33, 296-306.

Nataro, J. P. \& Kaper, J. B. (1998). Diarrheagenic Escherichia coli. Clin Microbiol Rev 11, 142-201.

Oswald, E., Schmidt, H., Morabito, S., Karch, H., Marches, O. \& Caprioli, A. (2000). Typing of intimin genes in human and animal enterohemorrhagic and enteropathogenic Escherichia coli: characterization of a new intimin variant. Infect Immun 68, 64-71.

Reece, S., Simmons, C., Fitzhenry, R. J., Matthews, S., Phillips, A. D., Dougan, G. \& Frankel, G. (2001). Site directed mutagenesis of intimin $\alpha$ modulates intimin-mediated tissue tropism and host specificity. Mol Microbiol 40, 86-98. 
Schauer, D. B. \& Falkow, S. (1993a). Attaching and effacing locus of a Citrobacter freundii biotype 4280 that causes transmissible murine colonic hyperplasia. Infect Immun 61, 2486-2492.

Schauer, D. B. \& Falkow, S. (1993b). The eae gene of Citrobacter freundii biotype 4280 is necessary for colonization in transmissible murine colonic hyperplasia. Infect Immun 61, 4654-4661.
Weis, W. I. \& Drickamer, K. (1996). Structural basis of lectincarbohydrate recognition. Annu Rev Biochem 65, 441-473.

Received 19 July 2001; revised 29 October 2001; accepted 6 November 2001. 